\title{
PLASMA FIBRINOGEN AND THE SEDIMENTATION RATE IN RHEUMATOID ARTHRITIS, AND THEIR RESPONSE TO THE ADMINISTRATION OF CORTISONE AND ADRENOCORTICOTROPIC HORMONE $(\mathrm{ACTH})^{1}$
}

\author{
By A. A. FLETCHER, J. A. DAUPHINEE, AND M. A. OGRYZLO 2 \\ (From the Clinical Investigation Unit, Sunnybrook (D.V.A.) Hospital, and the Departments \\ of Medicine and Pathological Chemistry, University of Toronto, Toronto, Canada)
}

(Submitted for publication February 6, 1952; accepted March 31, 1952)

The purpose of this communication is to report on our investigations into the relationship between the erythrocyte sedimentation rate and the level of the plasma fibrinogen in patients with rheumatoid arthritis, and to describe the effect of the administration of cortisone and ACTH upon this relationship. It will also show that the sedimentation rate often fails to reflect the high rebound levels reached by the blood fibrinogen during the relapse period which follows the abrupt termination of treatment with these hormones.

\section{HISTORICAL}

In 1918 and in 1921 Fahraeus (1) drew attention to a new form of clinical examination of the blood, the determination of the sedimentation velocity of the red blood corpuscles. Since that time this determination has been used extensively in the investigation of patients, and has been shown to be of particular value in assessing the intensity or the continued activity of a number of disease processes. Much investigation has been carried out in an effort to determine the factors responsible for the changes in the sedimentation rate. Fahraeus (2) and many others have pointed out that the erythrocyte settling velocity may be affected by a number of factors. These include the size, shape, and numbers of the red blood cells, the viscosity of the plasma, the plasma content of cholesterol, lecithin, nucleoprotein, and the presence in the blood of abnormal globulins or other substances having a large asymmetric molecular. configuration. In his review of 1929, Fahraeus

\footnotetext{
1 This study was assisted by a grant-in-aid from the Canadian Arthritis and Rheumatism Society.

2 Canadian Arthritis and Rheumatism Society Fellow in Medicine.
}

(2) expressed the opinion that although the sedimentation rate can be influenced by many factors, it is in the main an expression of the size of the particles formed by the aggregated rouleaux of the red blood cells, when clotting is prevented. He also expressed the belief that while the size of these particles is determined by certain changes in the surface layer of the erythrocytes, these changes are dependent upon the properties of the blood plasma rather than upon any intrinsic alteration in the cells themselves. He stated that the principal factor responsible for this clumping effect is the concentration of the plasma fibrinogen, and that in most cases a marked parallelism exists between the amount of fibrinogen present and the sinking velocity of the erythrocytes. A similar but less marked influence is exerted by the plasma globulin. These observations and opinions of Fahraeus have been supported by many investigators and challenged by others (3).

In 1938, Ham and Curtis (4) reviewed the significance of the sedimentation rate as a laboratory aid in clinical medicine. They concluded that the rate of settling of the red blood cells, as determined by the method of Rourke and Ernstene (5), showed a rough linear correlation with the concentration of plasma fibrinogen, providing that the serum globulin, the mean corpuscular volume, and the corrected defibrinated sedimentation rate were all within normal limits. The degree of correlation was only slightly less when the Westergren (6) method was used.

Gray and Mitchell (7), by the addition of various electrophoretically homogeneous fractions of plasma to blood, have demonstrated that the accelerating effect of fibrinogen upon the sedimentation rate is roughly six times that of serum globulin. 
Gordon and Wardley (8) made similar observations but noted that the relationship between the plasma fibrinogen and the sedimentation rate was not always a simple one. They suspected the existence of a complex inhibiting influence of one protein upon another.

In 1946, Malmros and Blix (9) published observations made over a period of eight years in patients showing high sedimentation rates and suffering from a variety of disorders. The globulins were estimated by the electrophoretic technique. They recognized the difficulty of correlating the sedimentation rate with the individual constituents of the plasma, and stated that the correlation would vary according to the clinical material used. For example, they reported cases of hyperglobulinemia of unknown origin, where the sedimentation rate was very high and the fibrinogen content of the plasma was normal. Similar observations were made in myelomatosis, nephrosis, and in liver disease.

It is well known that there is an increase in the plasma fibrinogen in many disease states, notably those of infection, inflammation and tissue injury or necrosis. Experimentally this response is inhibited or abolished when the liver is severely damaged, and it has been assumed that the liver is the source of the increased fibrinogen $(10,11)$.

There is general agreement that in patients suffering from rheumatoid arthritis, the settling velocity of the red blood cells is an indication of the activity of the disease process, perhaps more so than in any other illness. Earlier studies by the senior author (12) on the plasma protein fractions in this disease have shown that, in the active stages, the elevated sedimentation rate is almost always accompanied by an increase in the level of the plasma fibrinogen, and in the majority of instances the serum globulins are not seriously altered.

Hench, Kendall, Slocumb, and Polley (13), in announcing the dramatic effect of cortisone and ACTH on the course of rheumatoid arthritis, stated that during the remission there was an abrupt fall in the sedimentation rate and that it rose again as the arthritis relapsed when the administration of the hormones was discontinued.

A year later, Vaughan, Bayles and Favour (14) reported that during the remissions induced by these hormones in rheumatoid arthritis, there occurred a rapid fall in the plasma fibrinogen and that this fall closely paralleled the fall in the sedimentation rate. They also noted a fall in the concentration of the gamma globulin but this was found to occur more slowly and usually lagged five to seven days behind the fibrinogen changes. In another paper (15) these investigators concluded that the decrease in the plasma fibrinogen and gamma globulin was responsible for the observed changes in the sedimentation rate. It seemed to them that the difference in the rates of response of these proteins to hormone therapy was probably due to differences in the rates of synthesis.

Ogryzlo and Graham (16) reported that in cases of Reiter's syndrome and rheumatoid arthritis treated with ACTH or cortisone, the level of plasma fibrinogen closely paralleled the clinical activity of the disease process and bore a close relationship to the erythrocyte sedimentation rate.

Fischel (17) has also stated that the depression of fibrinogen and gamma globulin, during hormone therapy, is not necessarily a primary effect of the hormone but appears more likely to be a reflection of the effect of the hormones on the inflammatory disease process present in the patients studied.

\section{MATERIALS AND METHODS}

The observations reported in this communication are based on the study of the level of the plasma fibrinogen and erythrocyte sedimentation rate in 160 patients with rheumatoid arthritis selected at random from the arthritis service of Sunnybrook (D.V.A.) Hospital, Toronto, since 1948. Three of these patients have been studied carefully in this way over a three year period. A1together the sedimentation rate has been compared with the plasma fibrinogen in over 1,000 instances.

With the advent of ACTH and cortisone, remissions may now be induced in such patients almost at will and over short periods of time. Such remissions have afforded an excellent opportunity for the further study of the relationship between the sedimentation rate and plasma fibrinogen. In the past two years this relationship has been followed at frequent intervals in 18 patients, both during the induction of the remissions and the subsequent relapses. A total of 27 such courses of therapy was studied.

Plasma fibrinogen has been determined by the method of Cullen and Van Slyke (18). The serum protein fractions have been separated by the sodium sulphite procedure of Campbell and Hanna (19) and quantitatively measured by the biuret technique of Gornall, Bardawill, 


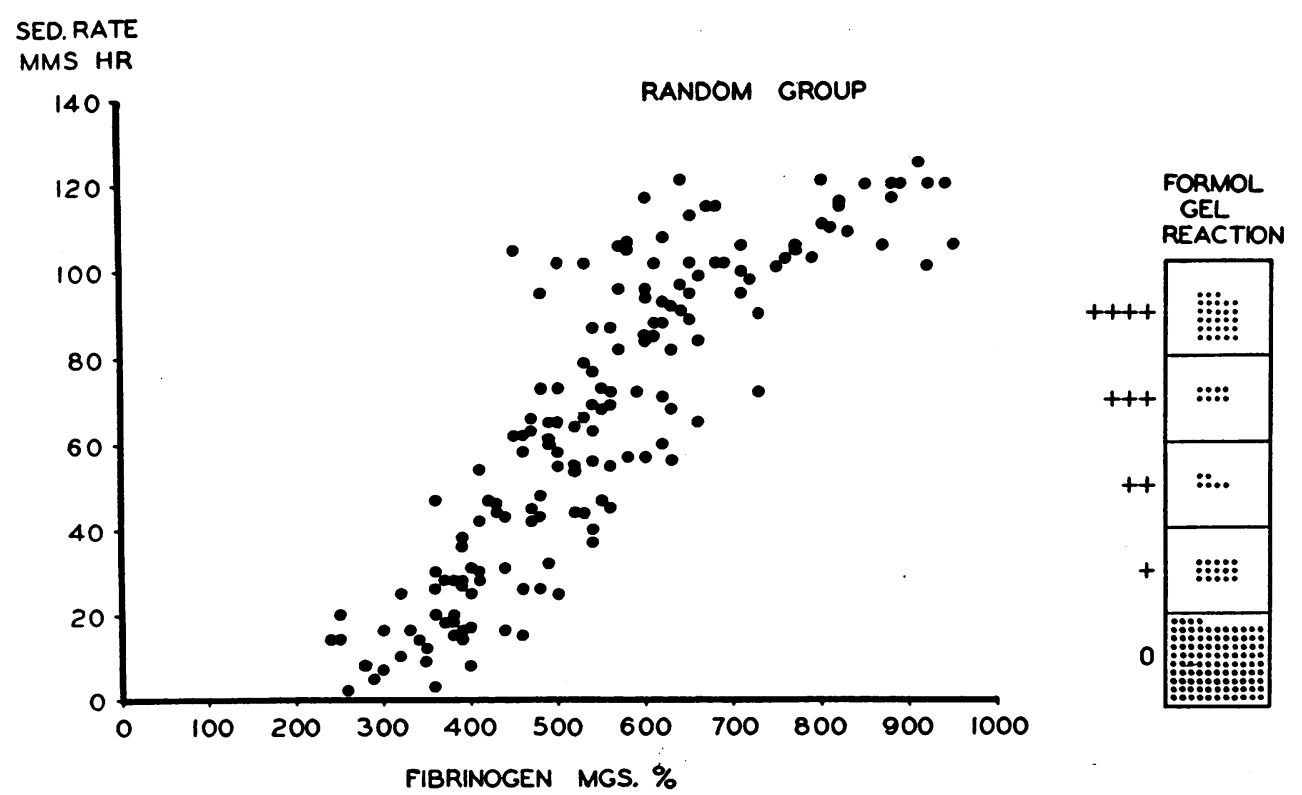

Fig. 1. Relationship of Plasma Fibrinogen to Sedimentation Rate in Rheumatoid ARTHRITIS

Coefficient of linear correlation, $r=0.869$. The qualitative serum formol gel reactions are also shown. (Formol gel reactions are recorded as follows: $0=$ no obvious change in viscosity after 24 hours; $+=$ mild to moderate increase in viscosity after 24 hours; $++=$ marked increase in viscosity but no definite gel after 24 hours; $+++=$ definite gel in 24 hours but gel is soft and not rigid; $++++=$ serum is a solid stiff gel in 24 hours or less.)

and David (20). The formol gel reaction (21), thymol turbidity, cephalin cholesterol flocculation and hemoglobin concentration were also determined. Gamma globulin was determined in a number of cases by Kunkel's flocculation method (22). The results of many of these latter observations will be considered in a subsequent report. The sedimentation rate has been determined by a modified Westergren method, 0.05 cubic centimeter of a 30 per cent solution of potassium oxalate being added to each 5 cubic centimeters of blood as an anticoagulant. Much care has been exercised to establish uniformity of technique.

\section{RESULTS}

Normal levels of plasma fibrinogen by the method employed have varied from 240 to 360 milligrams per cent. The normal range given by Ham and Curtis (23) was 190-330 milligrams per cent. In active rheumatoid arthritis the fibrinogen content of the blood is almost always raised, and levels as high as 700 or 800 milligrams per cent are not infrequently observed. The highest level reached in this present study was 1,130 milligrams, during a period of relapse following a course of administration of cortisone.
The relationship of the plasma fibrinogen to the sedimentation rate in rheumatoid arthritis is shown in Figure 1, where the fibrinogen content of the blood has been plotted against the sedimentation rate. In this scattergram there is a rough linear correlation between the fibrinogen concentration and the sedimentation rate. Fibrinogen levels from 250 to 350 milligrams per cent are associated with a sedimentation rate below 20 millimeters in one hour. Concentrations of fibrinogen above this level are associated with progressively higher rates, reaching a maximum of 100 millimeters or over as the blood fibrinogen rises to 600 or 700 milligrams per cent. As is apparent, there is a considerable spread in the position of individual dots representing this relationship for any one level of fibrinogen. Other factors besides the fibrinogen content must influence the settling velocity of the cells and consequently the exact position of the dots. The spread appears much more marked for the high rates of sedimentation.

When patients with levels of total serum globu- 


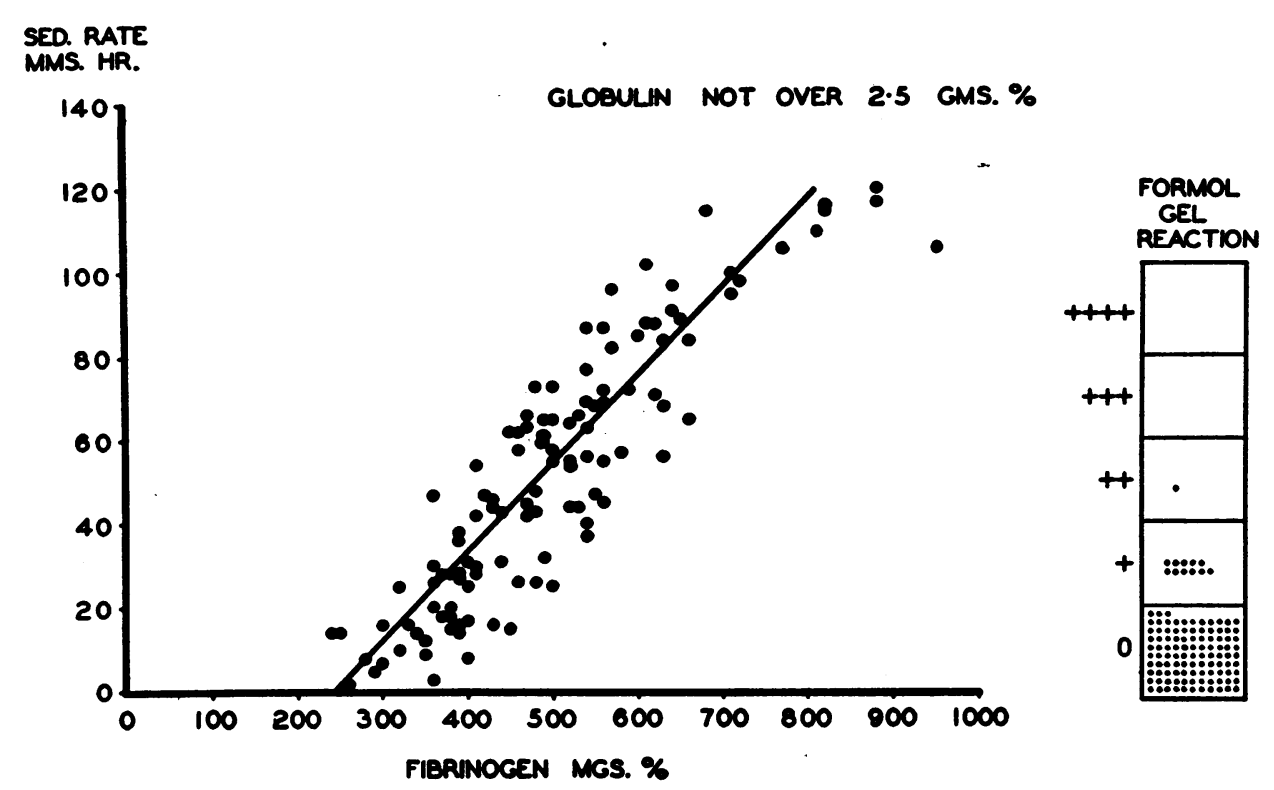

Fig. 2. Relationship of Plasma Fibrinogen to Sedimentation Rate in Patients with Serum Globulin Values not Exceeding 2.5 Grams Per Cent

Coefficient of linear correlation, $r=0.897$.

lin over 2.5 grams per cent (as determined by precipitation with 19 volumes of 21 per cent sodium sulphite) are excluded from the group, the resulting scattergram exhibits a better correlation (Figure 2). Much of the spread at the higher rates of sedimentation is eliminated. Considerable spread, however, persists and analysis of our data has shown that it is not diminished by allowing for variations in the hemoglobin content of the blood. Four or five patients with hemoglobin

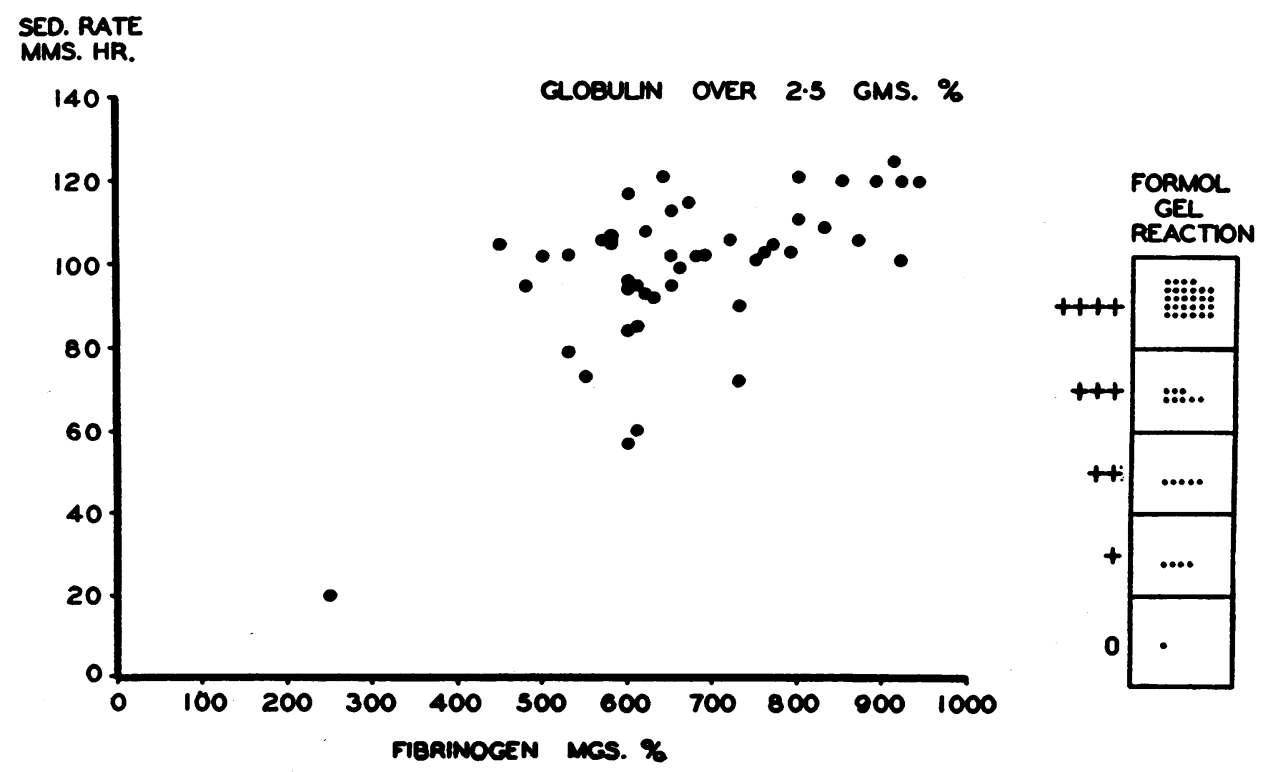

Fig. 3. Relationship of Plasma Fibrinogen to Sedimentation Rate in Patients with Serum Globulin Values Exceeding 2.5 Grams Per Cent

Coefficient of linear correlation, $r=0.599$. 
levels below 9.9 grams per 100 cubic centimeters were excluded from this series. The coefficient of linear correlation for this group of patients is high $(r=0.897) .^{8}$ The regression line runs from about 250 milligrams per cent of fibrinogen at a sedimentation rate of 0 millimeter, and reaches 700 milligrams per cent at a sedimentation rate of 100 millimeters.

In Figure 3, a scattergram is shown for patients in whom the serum globulin is in excess of 2.5 grams per cent. Here the correlation is not nearly as good, but it may be pointed out that in this group (with one exception, globulin 2.6 grams per cent) the sedimentation rate was high, and in the ma-
2.5 grams per cent, this reaction begins to become positive and at levels above 3.0 grams per cent is almost always strongly positive. This is in agreement with the statement made that the formol gel reaction may be employed to obtain a rough estimation of the degree of hyperglobulinemia (24).

A typical response of the blood fibrinogen and the sedimentation rate to the administration of ACTH is shown in Figure 4. This occurred in a case of severe rheumatoid arthritis of ten years duration. The patient was a 35 year old army veteran who had had no previous remission during his three year stay in hospital, despite prolonged treatment with bed rest, various physical

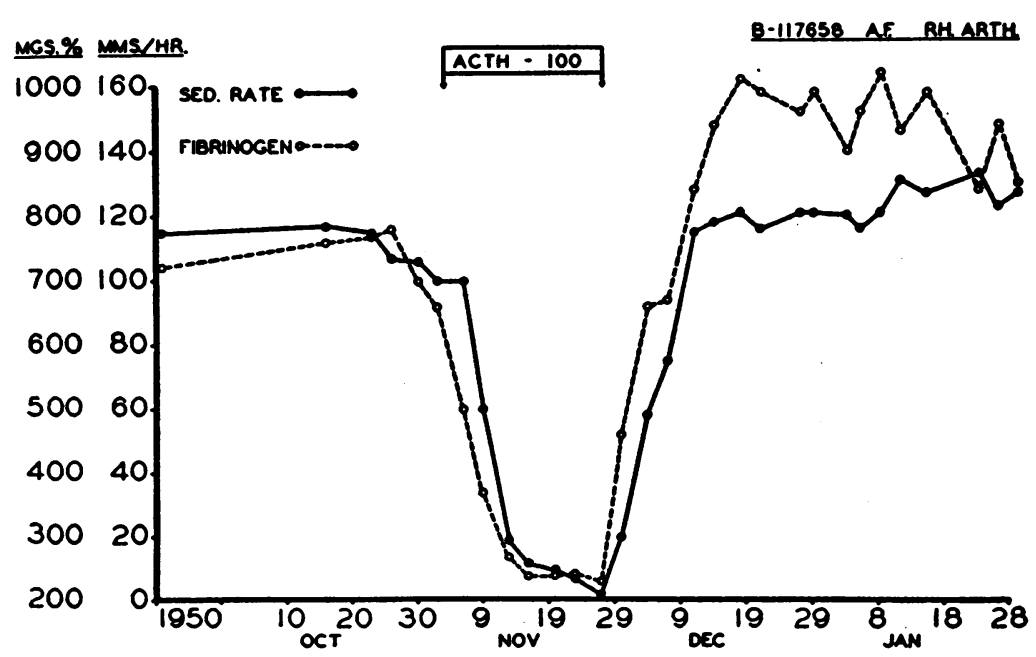

Fig. 4. The Effect of a 24 Day Course of ACTH on the Sedimentation Rate and Plasma Fibrinogen in a Patient with Rheumatoid ARTHRITIS

Note the high rebound of the plasma fibrinogen.

jority of instances was over 80 millimeters in one hour. While it is evident in these that the globulin is playing some part in the accelerated rate of sedimentation, in most of them the fibrinogen is also raised and the effect of the globulin is to a large degree masked by the elevated fibrinogen.

In Figures 2 and 3 the results of the qualitative serum formol gel reaction are shown. When the globulin level is below 2.5 grams per cent, this reaction has usually been negative or occasionally weakly positive. When the globulin rises above

3 The authors are indebted to A. J. Phillips, Ph.D., statistician, National Cancer Institute of Canada, for the statistical analysis of this report. measures and the administration of gold salts. ACTH, 100 milligrams daily, was given in divided doses over a period of 24 days. During this time the patient underwent an almost complete clinical remission. However, as soon as the treatment was stopped he began to relapse and within seven days his condition had returned to its original severity. During the remission, as is shown in Figure 4, the plasma fibrinogen fell from 660 milligrams per cent to 370 milligrams per cent in the first seven days, and to 240 milligrams per cent after 14 days. When the ACTH was discontinued, the fibrinogen level rose rapidly and abruptly to pretreatment levels within eight days 
time, and continued to rise until it reached $1,010^{\circ}$ milligrams per cent, 14 days later. From this level it gradually dropped to the pretreatment figure.

In the figure, the sedimentation rates are plotted in such a way that a value of 100 millimeters per hour will correspond to a fibrinogen level of 700 milligrams per cent, and a rate of 0 millimeters to a fibrinogen of 200 milligrams. The correlation in this case when this is done is very close indeed, both during the remission and during the relapse periods. When the sedimentation rate reached 100 millimeters, however, it failed to follow the rising fibrinogen level, and for the next six weeks did not reveal the high rebound figures reached by the fibrinogen.

During both the remission and the relapse, the change in the plasma fibrinogen preceded that of the sedimentation rate by 24 to 48 hours, although the curves remain essentially parallel. This lag phenomenon results in the temporary dislocation of the interrelationship. It is well illustrated in Figure 4, where at one point the fibrinogen level has fallen to 500 milligrams, although the sedimentation rate is still 100 millimeters. A similar lag is observed during the relapse, when a fibrinogen of 460 milligrams is associated with a sedi- mentation rate of only 20 millimeters. Obviously single estimations made during times of rapid change will fail to reveal the close interrelationship.

The various relationships during the induction of two remissions and two relapses in the same patient are plotted in scattergram fashion in Figure 5. The round and square closed dots represent two successive remissions; the round and square open dots, two successive relapses. The line joining the dots, representing the successive relationships between the fibrinogen and sedimentation rates at various stages of the remission and relapse, is seen to follow a definite pattern. With the onset of a remission there occurs initially a decrease in the level of plasma fibrinogen without a corresponding decrease in the sedimentation rate, with the result that the curve moves to the left of the regression line. After 24 to 48 hours, the sedimentation rate also begins to fall and thereafter they both fall in such a way that the curve indicating their interrelationship passes downwards, to the left of and parallel to the regression line. When low levels are reached and the remission is complete, the dots return to the regression line. When treatment is stopped and the relapse begins, the situation is seen to be reversed. At the beginning of the relapse fibrinogen is in-

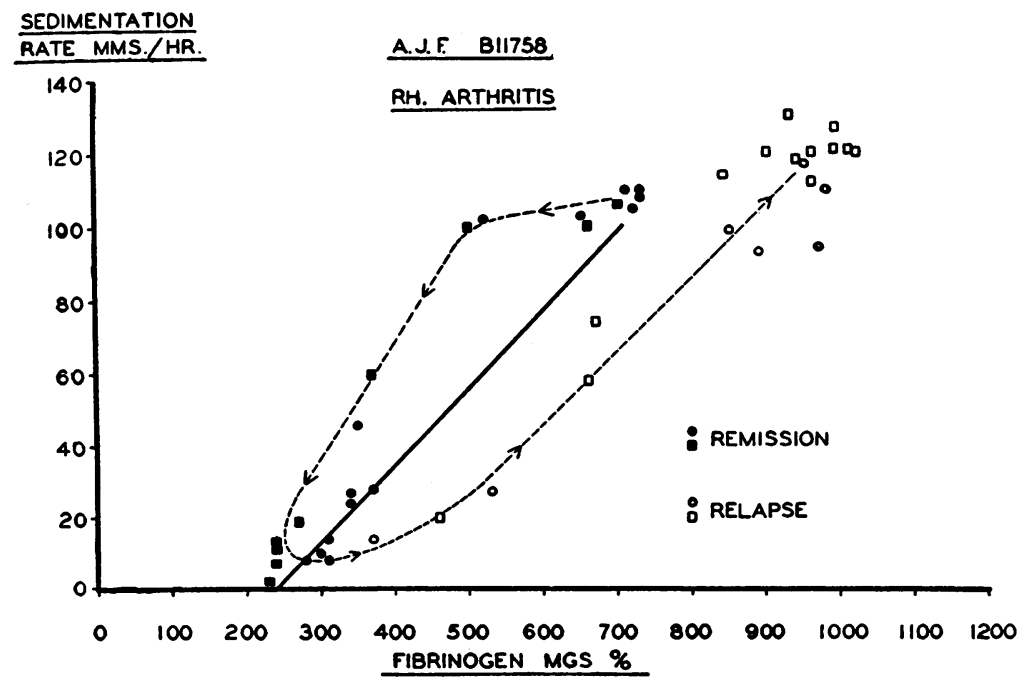

Fig. 5. The Progressive Interrelationships of Sedimentation Rate and Plasma Fibrinogen during Two Successive Remissions and Relapses Induced by ACTH and Cortisone in a Patient with Rheumatoid Arthritis

The course of the curve has the form of the letter "C." 
creased without there being any change in the sedimentation rate. As a result the curve moves to the right. It then rises roughly parallel to the regression line. Finally a group of dots at the end of the curve show the high levels of fibrinogen that were observed during the rebound period.

The curve thus obtained has the appearance of the letter " $U$ " or the letter "C." The shape of the curve is similar in all cases when such a remission is induced. The curve may be largely or entirely to the left or to the right of the regression line depending upon the initial relationship of the fibrinogen and the sedimentation rate. The downstroke and upstroke of the curve run parallel or nearly so to the regression line.

Figures 4 and 5 both demonstrate that when the blood fibrinogen rises above 700 milligrams per cent, a further increase is not indicated by the sedimentation rate. This of course is not unexpected, since a rate of 100 millimeters in one hour, in the absence of anemia, has already nearly
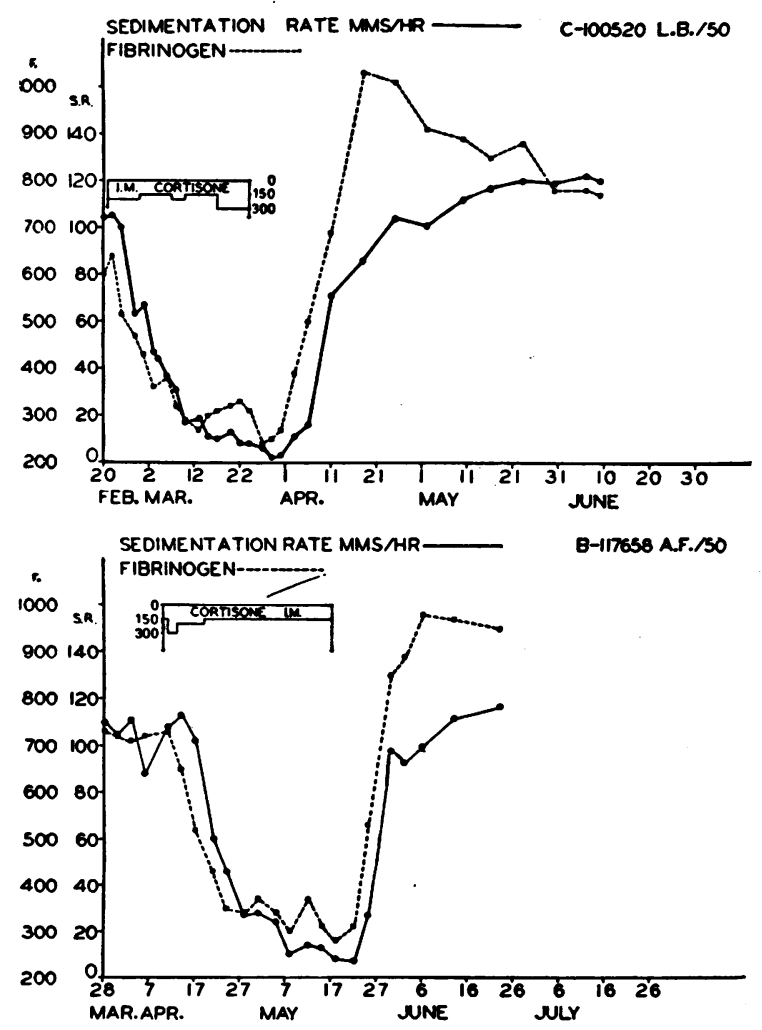

reached its maximum speed. The pattern of the change in most patients studied has been uniformly similar, with few minor variations (Figure 6).

In contrast to the above observations, the changes occurring in the levels of the serum euglobulin (as measured by precipitation with 19 volumes of 15 per cent sodium sulphite), and the gamma globulin (as estimated by Kunkel's flocculation method), are of a different order and roughly parallel one another. Both fail to show any close correlation to the rate of erythrocyte sedimentation. During the onset of a remission the euglobulin and gamma globulin concentrations both fall, but the decrease is more gradual than that which occurs in the fibrinogen level (Figures 7 and 8). Furthermore both of these constituents may continue to fall for an appreciable period after hormone therapy has been discontinued, even though the fibrinogen and the sedimentation rate have started to rise and clinical relapse has begun. Eventually, however, the euglobulin and gamma
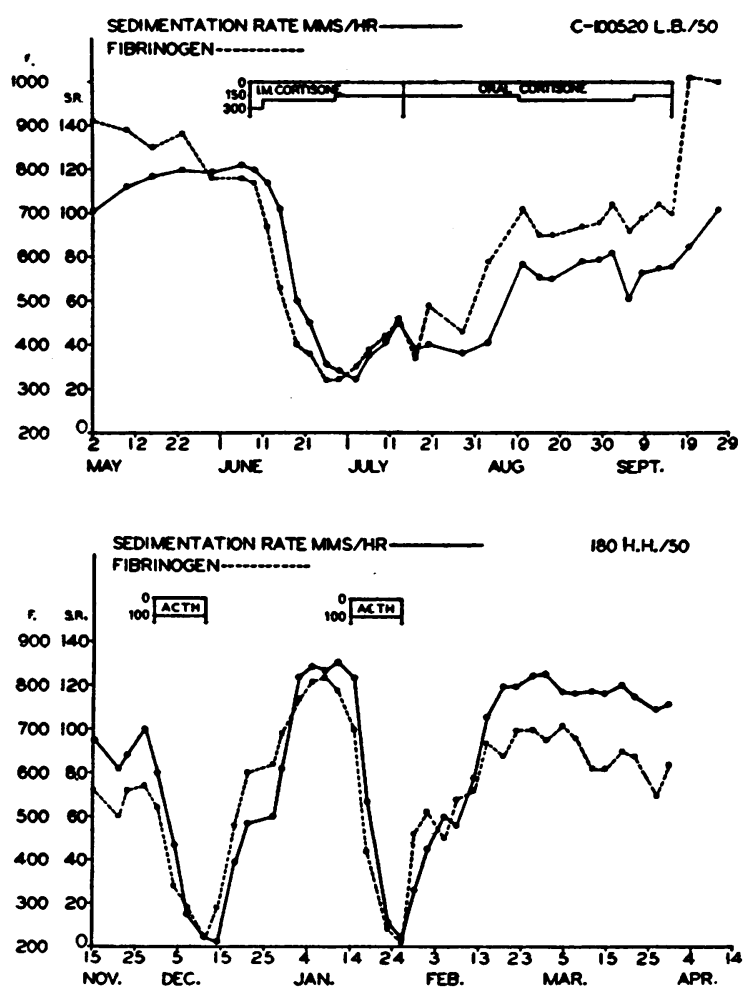

Fig. 6. Four Illustrative Cases Showing the Effect of Cortisone and ACTH on the Plasma Fibrinogen aNd Sedimentation Rate in Rheumatoid Arthritis

Note that the fall in fibrinogen precedes that of the sedimentation rate in all instances. 


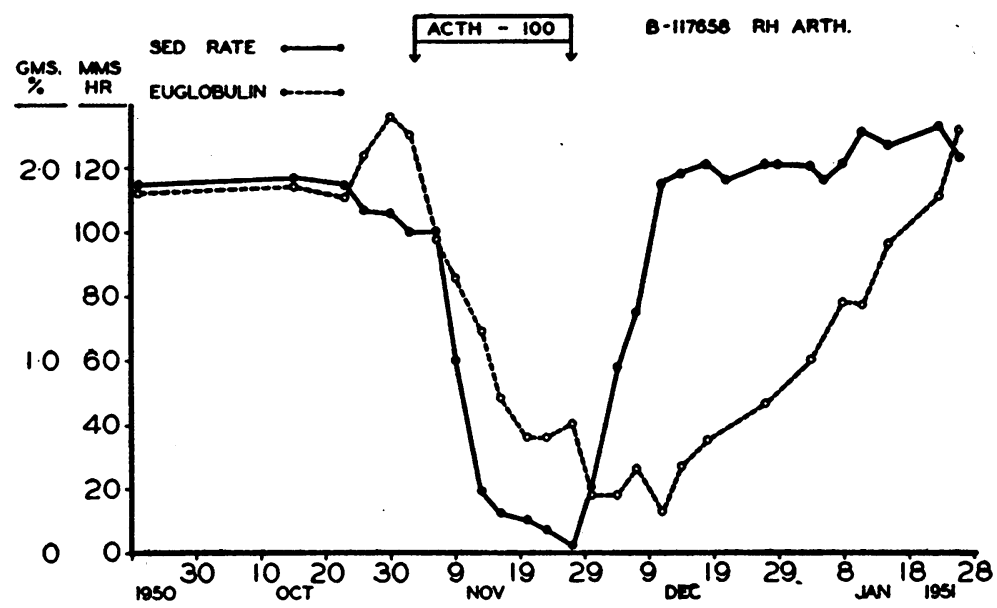

Fig. 7. The Effect of a 24 Day Course of ACTH on the Sedimentation Rate and Serum Euglobulin in a Patient with Rheumatoid ARThRITIS

Note that the changes in the euglobulin lag behind those in the sedimentation rate. The two curves show no parallelism. Compare with Figure 4.

globulin return to their pretreatment levels, or may temporarily exceed these. Not infrequently the euglobulin may drop to levels considerably below normal, a feature rarely observed in regard to the plasma fibrinogen. In Figure 7 the euglobulin fell from an abnormally high level of 2.27 to 0.21 gram per cent, as compared with a normal range of 0.5 to 1.0 gram per cent. After withdrawal of hormone therapy the euglobulin rose slowly and reached pretreatment levels about two months

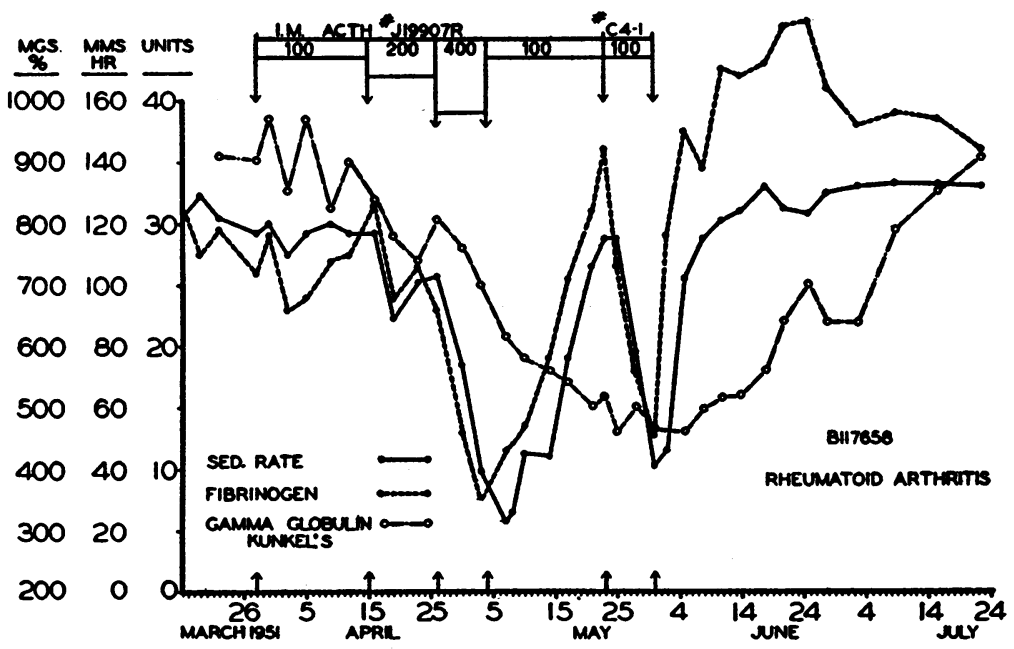

Fig. 8. The Effect of aCth on the Sedimentation Rate, Plasma Fibrinogen and the Gamma Globulin in a Patient with Rheumatom Arthritis

A typical remission was induced with 400 milligrams daily of a preparation of low potency, but clinical relapse occurred when this was reduced to 100 milligrams daily. Note that the fibrinogen and sedimentation -rate parallel the clinical course, while the gamma globulin fails to indicate the relapse in the disease. A further remission took place with the administration of an active preparation in the same dosage. 
later. As shown in Figure 8, a clinical relapse occurred while the patient was receiving 100 milligrams daily of an ACTH of low potency. The relapse was reflected closely by the sedimentation rate and the plasma fibrinogen, but it was not reflected by the gamma globulin, presumably because this globulin is not capable of indicating rapid changes in the clinical state.

\section{DISCUSSION}

Our observations made prior to the introduction of cortisone and ACTH have been in agreement with those of Fahraeus, and of Ham and Curtis; viz., that the sedimentation rate is a rough index of the blood fibrinogen level in patients with rheumatoid arthritis when there is no abnormality in the globulin content and in the absence of severe anemia. The raised fibrinogen level in turn appears to be a reaction to the inflammatory process or tissue injury. The clinical material studied contains a number of early and comparatively mild cases, the large majority of which showed little or no globulin elevation. In these the sedimentation rate seemed to be an index of the intensity of the disease reaction rather than one of the severity or gravity of the disease itself. In this way it is comparable to the significance of fever or leucocytosis. Even when the globulin level is raised (or when the serum formol gel reaction is strongly positive), the high sedimentation rates of rheumatoid arthritis will, as a general rule, be associated with an elevated plasma fibrinogen.

A scattergram showing the various fibrinogen concentrations plotted against the sedimentation rate has provided an average regression line indicating the interrelationship and also shows the degree of deviation which may occur.

With the fall in the plasma fibrinogen and sedimentation rate which accompanies a partial or complete remission induced by ACTH or cortisone in patients with rheumatoid arthritis, the relationship of the sedimentation rate and the plasma fibrinogen is to a large extent maintained, except that there is a lag in the sedimentation rate fall of 24 to 48 hours. The lag is also observed during the relapse period which sets in on withdrawal of the hormone. This results in a temporary but quite material dislocation in the relationship during the time of rapidly changing levels. This dis- location of the interrelationship is not inconsistent with present theories of the mechanism underlying the sedimentation rate. The increased settling velocity of the red cells appears to be directly related to the size of the particles of aggregated rouleaux and the formation of these large particles is thought to be dependent upon the increased adhesiveness or stickiness of the red cells brought about by the large fibrinogen or globulin molecules. This theory has been discussed in detail by Ponder (25). In the light of this conception it would seem likely that the red cells are not immediately influenced by changing blood fibrinogen, and that some time interval must elapse before the cells assume the adhesiveness which should correspond to a new concentration of the plasma protein. The course of the sedimentation rate during rapid changes of blood fibrinogen might then be said to offer material support to this concept of their interrelationship.

It has also been shown that, during the relapse which sets in when hormone administration is stopped, the blood fibrinogen may rise to as high as 50 per cent above pretreatment levels. These rebound figures appear to indicate an actual increase in the intensity of the arthritic process. In one patient an intractable iridocyclitis developed at this time. Other patients also have appeared worse during the rebound period than before initiating hormone therapy. The occurrence of such reactions constitutes a possible menace and might be a warning against the abrupt cessation of treatment in severe cases.

The significance of the behavior of blood fibrinogen following hormone therapy has been a subject of some controversy. One might expect that the level of this protein would continue to be an index of tissue inflammation or injury and would reflect the hormonal suppression of the intensity of the disease. Recently Vaughan, Bayles, and Favour (15) have questioned this view and have stated that it is also reasonable to assume that the changes in protein levels are the result of direct action of the cortical steroids upon their production. Such an effect would be consistent with the anti-anabolic properties of these hormones. It does seem that at times this anti-anabolic effect may be evident and the fibrinogen level may fall beyond what might be expected in the light of the 
degree of clinical improvement. However, this effect appears to be a minor one when the levels of fibrinogen are changing rapidly. As a rule the level of the fibrinogen follows fairly well the course of the remission and the relapse. In exceptional cases where there is a poor clinical response, there is only a partial fall in the blood fibrinogen. The high figures which may be reached during the rebound period probably indicate increased intensity of the disease. It has been further noted that with the induction of a complete remission the fibrinogen usually falls to within the normal range. In 27 courses of treatment it fell only once below the normal minimum of 190 milligrams per cent. On this occasion the fibrinogen reached a low value of 140 milligrams per cent. This behavior is in contrast to that of the euglobulin fraction. Not infrequently, the euglobulin may drop far below normal even with little clinical improvement, and here the response is more suggestive of hormonal suppression of protein synthesis. The fall in euglobulin is slower than that of fibrinogen and may continue after hormone administration has been stopped and a relapse is setting in. Certainly the euglobulin figures appear to be far less related to the activity of the arthritis. It is of interest to note in this connection, however, that both the total globulin and euglobulin may also ultimately rise to well above pretreatment levels. The significance of this is as yet far from clear.

\section{SUMMARY}

In rheumatoid arthritis, the sedimentation rate, as determined by the uncorrected Westergren technique, is a fair index of the level of the plasma fibrinogen, providing that the serum globulins are not markedly elevated and in the absence of severe anemia. Even when the globulin fractions are increased, a high sedimentation rate is usually associated with an elevated blood fibrinogen. The elevated fibrinogen content of the blood in turn appears to be an expression of the intensity of the disease process.

The administration of cortisone or ACTH in amounts sufficient to induce a clinical remission usually results in a dramatic fall in both the sedimentation rate and in the plasma fibrinogen, often to normal levels. During the relapse which follows the withdrawal of the hormones, both usually rise again. The plasma fibrinogen seems to continue to reflect the intensity of the disease during the period of these rapid changes, although the sedimentation rate may lag by 24 to 48 hours, resulting in a temporary disturbance in their interrelationship.

In the relapse or "rebound" period following abrupt cessation of hormone therapy the plasma fibrinogen was found frequently to rise not only to the pretreatment levels but to values which were as much as 50 per cent above those which existed before treatment. Since the sedimentation rate does not reflect fibrinogen concentrations above 700 milligrams per cent, it does not reveal the high rebound fibrinogen levels which may occur during the relapse period.

Changes in the serum globulins occur more slowly and present comparatively little relationship to the sedimentation rate or to the intensity of the arthritis. During the remissions induced by hormone therapy these serum proteins may fall well below their normal concentrations.

\section{ACKNOWLEDGMENT}

Grateful acknowledgment is made to Mrs. Bruce Frain and Mrs. Susan Saito for technical assistance; to Dr. T. E. Hunt and Dr. Bruce Frain for clinical assistance and to Dr. Wallace Graham and Dr. Donald Grabam for access to many patients under their care.

\section{REFERENCES}

1a. Fahraeus, R., Om Hamägglutationen Särskilt med Hänsyn Till Havandeskapet och Möjligheten avatt Diagnostiskt Utnyttja Densamma. Hygeia, 1918, 80, 369.

b. Fahraeus, R., The suspension stability of the blood. Acta med. Scandinav., 1921, 55, 3.

2. Fahraeus, R., The suspension stability of the blood. Physiol. Rev., 1929, 9, 241.

3. Gutman, A. B., The plasma proteins in disease, in Advances in Protein Chemistry, edited by Anson, M. L., and Edsall, J. T. The Academic Press, Inc., New York, 1948, Vol. IV, p. 225.

4. Ham, T. H., and Curtis, F. C., Sedimentation rate of erythrocytes: influence of technical, erythrocyte and plasma factors and quantitative comparison of five commonly used sedimentation methods. Medicine, 1938, 17, 447.

5. Rourke, M. D., and Ernstene, A. C., A method for correcting the erythrocyte sedimentation rate for variations in the cell volume percentage of blood. J. Clin. Invest., 1930, 8, 545.

6. Westergren, A., The technique of the red cell sedi- 
mentation reaction. Am. Rev. Tuberc., 1926, 14, 94.

7. Gray, S. J., and Mitchell, E. B., Effect of purified protein fractions on the sedimentation rate of erythrocytes. Proc. Soc. Exper. Biol. \& Med., 1942, 51, 403.

8. Gordon, C. M., and Wardley, J. R., The effect of the plasma proteins upon the sedimentation rate of human blood. Biochem. J., 1943, 37, 393.

9. Malmros, H., and Blix, G., The plasma proteins in cases with high erythrocyte sedimentation rate. Acta med. Scandinav., 1946, Supp. 170, 280.

10. Whipple, G. H., Fibrinogen. I. An investigation concerning its origin and destruction in the body. Am. J. Physiol., 1914, 33, 50.

11. Mann, F. C., and Bollman, J. L., The influence of complete removal of the liver on the factors concerned in the coagulation of the blood. Proc. Staff Meet., Mayo Clinic, 1929, 4, 328.

12. Fletcher, A. A., and Kelly, H. G., Unpublished data.

13. Hench, P. S., Kendall, E. C., Slocumb, C. H., and Polley, H. F., The effect of a hormone of the adrenal cortex (17-hydroxy-11-dehydrocorticosterone: compound E) and of pituitary adrenocorticotropic hormone on rheumatoid arthritis; preliminary report. Proc. Staff Meet., Mayo Clinic, 1949, 24, 181.

14. Vaughan, J. H., Bayles, T. B., and Favour, C. B., The effect of ACTH on blood complement, gamma globulins and fibrinogen. J. Clin. Invest., 1950, 29, 850.

15. Vaughan, J. H., Bayles, T. B., and Favour, C. B., Effect of 17-hydroxy-11-dehydrocorticosterone and adrenocorticotropic hormone upon plasma gamma globulin, fibrinogen and erythrocyte sedimentation rate. Proc. Soc. Exper. Biol. \& Med., 1951, 76, 274. 16a. Ogryzlo, M. A., and Graham, W., Reiter's syndrome : effect of pituitary adrenocorticotropic hormone (ACTH) and cortisone. J. A. M. A., 1950, 144, 1239.

b. Ogryzlo, M. A., Discussion section; The significance of sedimentation rate changes during ACTH therapy, by Robinson, W. D., Wolfson, W. Q., and Duff, I. F., in Proceedings of the Second Clinical ACTH Conference, edited by Mote, J. R. The Blakiston Co., Philadelphia, 1951, Vol. II, p. 565.

17. Fischel, E. E., Cortisone and erythrocyte sedimentation (in Correspondence). J. A. M. A., 1951, 146, 1340.

18. Cullen, G. E., and Van Slyke, D. D., Determination of the fibrin, globulin, and albumin nitrogen of blood plasma. J. Biol. Chem., 1920, 41, 587.

19. Campbell, W. R., and Hanna, M. I., The albumin, globulins and fibrinogen of serum and plasma. $\mathrm{J}$. Biol. Chem., 1937, 119, 15.

20. Gornall, A. G., Bardawill, C. J., and David, M. M., Determination of serum proteins by means of the biuret reaction. J. Biol. Chem., 1948, 177, 751.

21. Bing, J., The formolgel reaction and other globulin reactions. Acta med. Scandinav., 1937, 91, 336.

22. Kunkel, H. G., Estimation of alterations of serum gamma globulin by a turbidimetric technique. Proc. Soc. Exper. Biol. \& Med., 1947, 66, 217.

23. Ham, T. H., and Curtis, F. C., Plasma fibrinogen response in man. Influence of the nutritional state, induced hyperpyrexia, infectious disease and liver damage. Medicine, 1938, 17, 413.

24. Gutman, A. B., The plasma proteins in disease. Loc. cit., p. 235.

25. Ponder, E., Sedimentation: blood, in Medical Physics, edited by Glasser, $O$. The Year Book Publishers, Inc., Chicago, 1944, p. 1408. 